\title{
Observatório de
}

Inovação do Turismo

BRASIL

Revista Acadêmica

ISSN 1980-6965

www.ebape.fgv.br/revistaoit

Sensacional!

\section{Empreendedorismo e formalização de atividades de turismo em ambientes naturais}

Entrepreneurship and formalization of tourism activities in natural environments

\author{
Ana Pimentel \\ Ayrton Violento \\ Camila G. de Oliveira Rodrigues \\ Danielle P. Julião \\ Ester Juer \\ Juliana Bastos Lohmann
}

\section{Resumo:}

No presente estudo, objetiva-se analisar algumas questões que permeiam as iniciativas empreendedoras no âmbito do turismo em ambientes naturais. Para tanto, parte-se do pressuposto de que o empreendedorismo é um processo que se constrói durante o percurso do negócio, isto é, desde sua concepção, estruturação, implementação e gestão do crescimento, que expõe macro e microelementos na sua dinâmica. Dessa maneira, apresentam-se as macrodimensões que sustentam o pilar do desenvolvimento dos negócios do turismo em ambientes naturais e ilustra-se o processo com um exemplo de empreendimento de turismo de aventura, denominado Lagoa Aventuras, situado no Parque Natural Municipal da Catacumba, na cidade do Rio de Janeiro, que serve para revelar uma microperspectiva do processo empreendedor. Assim, procura-se demonstrar a articulação dessas dimensões para compreender melhor a dinâmica do processo de empreendedorismo.

Palavras-chave: Empreendedorismo; Ambientes Naturais; Turismo; Unidades de Conservação.

Recebido em dezembro de 2011 e aceito em janeiro de 2013. 


\section{Abstract:}

This article aims to describe some aspects that entrepreneur initiatives in the tourism trade area encounter and deal with, in natural environment areas. For that purpose, the essay presents a short debate about the entrepreneurial definitions, besides addressing some legal issues that support the development of businesses as a consequence of the increase of tourism activities in natural environments. In order to illustrate the background theme of the paper, the case study of an adventure tourism enterprise will be presented: Lagoa Aventuras, located at the Municipal Natural Park Catacumba in the city of Rio de Janeiro.

Key words: Entrepreneur activities; natural environments areas; tourism

\section{Introdução}

Por meio de estudos do empreendedorismo, admitem-se uma microperspectiva, que enfoca o comportamento, competências e habilidades dos indivíduos, quanto uma macroperspectiva, que enfoca fatores ambientais, sociais e econômicos de uma determinada sociedade. Ambas são importantes para propiciar o entendimento da complexidade intrínseca ao processo empreendedor.

Pela macroperspectiva, abordam-se fatores ambientais referentes às variáveis econômicas, financeiras e política do país ou da região. Esses fatores geralmente extrapolam o controle do empreendedor, entretanto servem de parâmetros para a tomada de decisões. Quanto à microperspectiva, por ela se adota uma abordagem centrada no indivíduo, baseada em valores construídos e no comportamento, que pode também estar atrelada a um grupo de pessoas, considerando suas a relação com os sócios, parceiros, investidores e clientes.

Gonçalves (2003,p.19) explica:

Empreender enseja quebrar uma lógica de mercado, modificar uma dinâmica até então válida e oferecer ao mercado um negócio realmente novo. Não é por outro motivo que inovação e criatividade andam de braços dados com o empreendedorismo".

Assim o empreendedor é aquele que vislumbra um negócio a partir da identificação de uma oportunidade/necessidade.

Segundo Dornelas (2008), a utilização dos processos criativos e o desenvolvimento de novos negócios por meio do empreendedorismo são fatores determinantes para a evolução e a geração de novos empregos, além de impulsionar o crescimento sustentável necessário para regiões 
emergentes. Nesta perspectiva, Dolabela (1999) aponta-os como "motores da economia" e agentes de mudanças. Indivíduos que geram inovação identificam e criam oportunidades de negócios, montam e coordenam novas combinações de recursos para extrair o máximo de benefícios de suas criações.

Recentemente, acompanhou-se o incremento da atividade empreendedora e o desenvolvimento dos pequenos negócios no Brasil. Em 2006, com a regulamentação da Lei Complementar 123/2006', o governo brasileiro assumiu formalmente um conjunto de propostas em favor das micro e pequenas empresas, contemplando as macrotemáticas referentes: ao sistema tributário, ao processo de formalização e à baixa dos empreendimentos, à simplificação das relações de trabalho, das regras civis e empresariais, ao incentivo à inovação tecnológica, entre outras.

O avanço nas políticas públicas para os pequenos negócios não se esgotou com a sanção da Lei Complementar 123/06. Diversos ajustes foram feitos nos anos posteriores com a aprovação das Les Complementares 127, 128 e 133, além do encaminhamento do projeto de Lei no 591/2010, que tramita no Congresso Nacional, como uma verdadeira oportunidade para corrigir o enquadramento do microempreendedor individual, das microempresas e das empresas de pequeno porte, e equalizar os problemas relativos ao ICMS, o parcelamento dos débitos tributários, entre outros. Isso significa, portanto, dizer que as políticas públicas direcionadas aos pequenos negócios, nos últimos cinco anos, vêm contribuindo para o aumento da formalização e do incentivo ao empreendedorismo. Não obstante, no dia 08 de abril de 2011, a presidenta Dilma Roussef anunciou a formalização de mais de um milhão de microeempreendedores no Brasil, após um pouco mais de um ano e meio de programa².

Com base nesse cenário, cabe destacar que, entre as atividades beneficiadas, estão contempladas muitas daquelas relacionadas à cadeia do turismo de forma direta e/ou indireta, tais como: o guia de turismo, albergues e outros alojamentos, bares e restaurantes.

Um aspecto importante para a oferta de serviços de qualidade e a expansão da atividade turística como um todo é a formalização dos empreendimentos do setor. Muitos destinos e segmentos possuem grande número de empreendedores na informalidade, e a falta de informação é um dos principais obstáculos para a legalização dos negócios, o que foi constatado na pesquisa de Imagem Sebrae 2010 (CHIANCA, 2011) e ratificado pelo Programa Empresa Formal, Turismo Legal³.

Segundo dados da Ecinf - pesquisa sobre Economia Informal Urbana por amostra de domicílios que busca identificar o papel e a dimensão do setor informal na economia brasileira - as atividades preponderantes no setor informal estão no comércio e na reparação. Entre as empresas

\footnotetext{
1 Sancionada em 14 de dezembro de 2006 ,é, na realidade, o Estatuto Nacional da Microempresa e da Empresa de Pequeno Porte. Atende aos pressupostos da Constituição federal de 1988 que garante o tratamento diferenciado e simplificado aos pequenos negócios. Todos os benefícios passaram a vigorar em 2006, com exceção do aspecto tributário que começou a valer em julho de 2007, com a entrada do Simples Nacional (Supersimples).

${ }^{2}$ http://blog.planalto.gov.br/categoria/cafe-com-a-presidenta-destaques/. Último acesso realizado em: 11 de abril de 2011. ${ }^{3}$ O programa Empresa Formal Turismo Legal visa promover e apoiar o processo de formalização das atividades turísticas no Brasil e é resultado de um convênio do Ministério do Turismo (MTur) com a Fundação Universa, o programa tem o suporte institucional do Serviço Brasileiro de Apoio às Micro e Pequenas Empresas (Sebrae).
} 
do setor informal, 88\% dos empreendimentos não tinham sequer constituição jurídica, e a maioria dos trabalhadores, apenas o ensino fundamental incompleto. (Ecinf, 2003).

Como política de incentivo à mudança desse cenário, criaram-se programas específicos, no Ministério do Desenvolvimento, Indústria e Comércio Exterior, baseados, na supracitada Lei Complementar 123/2006. Por meio da Lei 11.771/2008, por exemplo, definiram-se condições para o funcionamento e a fiscalização de atividades e serviços empresariais.

Assim, neste artigo, será dirigida especial atenção à dinâmica que se apresenta entre os macro e microaspectos do processo do empreendedor e da formalização dele no âmbito do turismo em ambientes naturais no Brasil. Este recorte deve-se ao crescimento contínuo desse tipo de atividade não apenas no País, como no restante do mundo_setor de grande destaque no quesito competitividade internacional (BRASIL, 2008).

Com a intenção de ilustrar a dinâmica do empreendedorismo e da formalização do setor, acrescentou-se à discussão a análise de uma empresa de turismo de aventura atuante no mercado turístico da Região Metropolitana do Rio de Janeiro, precisamente dentro do Parque Municipal da Catacumba. Como metodologia, utilizaram-se, além de entrevista com um dos sócios do empreendimento, visitas ao local, pesquisas bibliográficas e documentais de alguns estudos, conversas informais e investigações via internet. Entre os estudos, destaca-se o Diagnóstico do Turismo de Aventura no Brasil (ABETA, 2009), a pesquisa realizada com os prestadores de serviços atuantes no segmento de turismo de natureza na Austrália (MCKERCHER, 2002), os resultados do projeto Empresa Formal Turismo Legal ${ }^{4}$ e a recente pesquisa realizada em cinco parques nacionais brasileiros pelo projeto piloto de Fomento ao Turismo em Parques Nacionais e Entorno, do Ministério do Turismo. Ver abaixo os principais eixos que contribuirão para o entendimento das questões acima apresentadas.

\section{Turismo em ambientes naturais: considerações conceituais e contextuais.}

O termo turismo em ambientes naturais será utilizado neste artigo como uma expressão ampla, que visa a abarcar diversas atividades realizadas em contato com a natureza, que também inclui o turismo de aventura 5 . Ao tratar de "ambientes naturais" no artigo, abarcam-se áreas protegidas, em especial as unidades de conservaçãó.

\footnotetext{
${ }^{4}$ O programa Empresa Formal Turismo Legal visa promover e apoiar o processo de formalização das atividades turísticas no Brasil e é resultado de um convênio do Ministério do Turismo (MTur) com a Fundação Universa, o programa tem o suporte institucional do Serviço Brasileiro de Apoio às Micro e Pequenas Empresas (Sebrae).

5 "Turismo de Aventura compreende os movimentos turísticos decorrentes da prática de atividades de aventura de caráter recreativo e não competitivo"(Mtur, 2006, p.39)

${ }^{6}$ Espaço territorial e seus recursos ambientais, incluindo as águas jurisdicionais, com características naturais relevantes, legalmente instituído pelo Poder Público, com objetivos de conservação e limites bem definidos, sob regime especial de administração, ao qual se aplicam garantias adequadas de proteção" (BRASIL, 2000).
} 
Cabe dizer, que embora existam peculiaridades conceituais e práticas distintas entre os segmentos do turismo praticados na natureza, considerar-se-á para efeito deste artigo o termo turismo em ambientes naturais para designar as atividades realizadas em contato com a natureza, uma vez que o enfoque não é a discussão conceitual dos segmentos, mas aspectos pertinentes ao empreendedorismo e as empresas do setor. Além disso, muitas empresas que atuam no turismo em ambientes naturais apresentam características similares, no que diz respeito à gestão, operação e mesmo ao porte do empreendimento.

A maior parte das empresas que opera no turismo, e não diferentemente no turismo em áreas naturais, é caracterizada por pequenas empresas, embora existam também alguns grandes operadores especializados em ecoturismo e turismo de aventura (McKercher, 2002; ABE$T A$,2009). Mas é crescente também o número de operadoras voltadas ao "turismo de massa", caracterizadas por atender um alto fluxo de clientes, pela composição de pacotes para grandes grupos, que comercializam viagens classificadas como "turismo de aventura" de forma equivocada. (McKercher, 2002)

Analisando a entrada de operadores de grande porte no turismo em áreas naturais, consideramos que esta pode representar um descompasso tanto para a sobrevivência das pequenas e médias empresas prestadoras de serviços, como também para a sustentabilidade dos destinos, incluindo os aspectos socioambientais do turismo e sua importância na diversificação e no fortalecimento da economia local. Essas operações de maior porte tendem a buscar baixos custos, pressionando os agentes receptivos locais para reduzir a sua margem de lucro, afetando em médio prazo a qualidade dos seus serviços. Isto quando as grandes operadoras não disponibilizam para o turista apenas a sua própria estrutura, excluindo do efeito multiplicador econômico do turismo os empreendedores locais, impactando inclusive na experiência e nas propostas do ecoturismo e do turismo de aventura.

A concorrência entre as empresas, as deficiências operacionais e gerenciais dos pequenos negócios somado à exigência de sustentabilidade dos destinos - pressionados pelas grandes operadoras - estão entre os aspectos propulsores da atividade empreendedora. Observa-se que os agentes e operadores de turismo de aventura atuam, de acordo com Fennell, (2002, p.138) "de forma a equilibrar a proteção e a restrição sem atrapalhar os operadores individuais. Isso representa um equilíbrio entre desenvolvimento e conservação, de oferta versus demanda, benefícios versus custos e população versus meio ambiente".

Outro aspecto importante quando se aborda o desenvolvimento do turismo em áreas naturais é a concessão dos serviços de apoio à visitação em unidades de conservação. Neste sentido deve-se realizar uma parceria entre as esferas pública e privada para a viabilização do empreendimento.

Portanto, na dimensão macro da atuação do empreendedor do turismo podemos destacar as políticas públicas de incentivo a formalização do empreendedor, a demanda de serviços relacionados 
ao turismo em áreas naturais, as exigências de sustentabilidade nestes destinos, a entrada do mercado das médias e grandes corporações, a necessidade de parcerias público/privado.

Nesta perspectiva, o presente trabalho tem o propósito de identificar e analisar as principais questões que permeiam as iniciativas empreendedoras no âmbito do turismo em ambientes naturais. Inicialmente abordaremos a noção de empreendedorismo, alguns marcos legais que sustentam o pilar do desenvolvimento dos negócios à luz do crescimento do turismo em ambientes naturais e, posteriormente, elucidaremos um exemplo de empreendimento de turismo em áreas naturais, situado no Parque Natural Municipal da Catacumba, na cidade do Rio de Janeiro. Desta maneira poderemos observar tanto a validade desses pressupostos, a dimensão macro das atividades empreendedoras, quanto a identificação das variáveis de dimensão micro, delineando assim a dinâmica do processo do empreendedorismo do turismo em ambientes naturais no âmbito brasileiro.

\section{0 empreendedorismo como processo}

De acordo com Baron \& Shane (2011) o empreendedorismo é uma área dos estudos de negócios que busca entender como surgem as oportunidades para criar novos produtos ou serviços, novos mercados, processo de produção, formas de organizar tecnologias existentes ou matérias-primas e como estas são criadas por pessoas que usam de vários meios para desenvolver um empreendimento e explorá-lo produzindo assim, uma vasta gama de efeitos.

Dentro da compreensão do empreendedorismo como um processo, questionam-se como os fatores no nível macro do processo de empreendedorismo tem favorecido ou limitado a inserção dos empreendedores locais na cadeia produtiva do turismo? E quais são os aspectos na perspectiva micro que tem favorecido ou limitado o processo empreendedor?

Os acontecimentos responsáveis por consolidar um empreendimento nem sempre são facilmente separados em fases bem delimitadas e distintas. Entretanto a tentativa de categorização traz benefícios, pois evita uma visão estática do empreendedorismo, além de chamar a atenção para as principais atividades que os empreendedores devem executar ao empreender. A competência empreendedora envolve além da geração de ideias de um novo produto ou serviço e/ou reconhecimento de uma oportunidade, a reunião dos recursos necessários para lançar o novo empreendimento, a administração e expansão da empresa, assim como a colheita da recompensa, entre outros.

Estudos sobre o empreendedorismo apontam para a observação das técnicas, habilidades, talentos, motivações e especificidades desse indivíduo ou no contexto econômico, tecnológico e social em que o empreendedor opera, isto é, as condições econômicas e mercadológicas e de políticas governamentais. Desta maneira entende-se o empreendedorismo como processo que se desenvolve ao longo do tempo. 
O empreendedorismo é afetado por diversos fatores, alguns relacionados aos próprios indivíduos, isto é, a relação com as demais pessoas, tais como: sócios, clientes, investidores. Além disso, existem as condições externas delimitadas pelas condições de mercado, regulamentações governamentais, entre outras. Todos estes fatores, a dizer, quanto ao indivíduo, grupo e sociedade, devem ser levados em consideração em cada fase do processo empreendedor. A dinâmica desse processo estaria na interseção entre as oportunidades geradas pelas condições sociais, tecnológicas e econômicas em transformação e as pessoas empreendedoras capazes de distinguir oportunidades valiosas e ser capaz de explorá-las.

Dentre as etapas do processo empreendedor podemos destacar: a inovação da ideia, a decisão de avançar, a implementação e o seu desenvolvimento. A cada uma dessas etapas existem condições externas a serem consideradas, mas também fatores individuais. Assim essa atividade dever ser entendida como sendo processual na qual devemos considerar: (1) as condições econômicas, tecnológicas e sociais das quais as oportunidades surgem; (2) as pessoas que reconhecem essas oportunidades, os empreendedores; (3) as técnicas de negócios e estruturas jurídicas que elas usam para desenvolvê-la; e (4) os efeitos sociais e econômicos produzidos por tal desenvolvimento. Vejamos abaixo:

1 - Reconhecimento de uma oportunidade. Representa o momento de criar algo novo da confluência de fatores externos, de um padrão complexo de condições constantemente em mudança como relação ao conhecimento, à tecnologia ou as condições econômicas, políticas, sociais e demográficas. As idéias não surgem do nada, elas são quase sempre uma combinação nova de elementos já existentes. A novidade é a combinação e não os componentes que fazem parte dela. As oportunidades são geradas por fatores econômicos tecnológicos e sociais.

2 - Avanço. Lançar um novo empreendimento. Reunir os recursos necessários, as informações básicas sobre mercados, questões ambientais e jurídicas. Recursos humanos, sócios, primeiros funcionários e recurso financeiros para sustentar o empreendimento.

3 - Implementação. Administrar um novo empreendimento e transformá-lo em uma empresa lucrativa em crescimento. Nessa etapa deve-se valorizar os recursos humanos, atrair pessoas talentosas e motivá-las e evitar que deixem a empresa. Conceber uma forte estratégia de negócios é outro aspecto do processo nessa fase. Conforme a estruturação do negócio, no decorrer das suas atividades, os empreendedores têm que enfrentar problemas como conflitos entre membros da equipe, atraso de fornecedores, ineficácia de parcerias, entre outros.

4 - Gestão para o crescimento. Para gerir uma empresa o empreendedor deve reconhecer as suas limitações, ser cuidadoso no recrutamento de uma equipe de trabalho competente para o ajudar na 
gestão da empresa, implementando ações que minimizem os problemas e maximizem os lucros, ou seja, produza mais, com o mínimo de recursos necessários, conjugando eficiência e eficácia.

Em cada fase do processo empreendedor estão presentes características, que contemplam variáveis individuais e interpessoais. Mas não apenas isso. Há de se levar em consideração a questão social, que contribui para a dinâmica dos acontecimentos - que nem sempre o empreendedor tem gerência sobre eles. Podemos citar como características pessoais: energia, disposição de correr riscos, autoconfiança, educação, experiência profissional.

Com relação ao grupo as características mais evidentes são: o incentivo de amigos, familiares, a vivência em ambientes empreendedores, entre outros. Como componente social: a legislação, as políticas públicas, a concorrência, e os recursos governamentais.

Não obstante, reforçamos que esses fatores individuais e sociais influenciam todas as fases do processo. Porém são as interseções entre as oportunidades valiosas captadas por indivíduos empreendedores que se encontra a dinâmica de construção do empreendedorismo.

\section{Os empreendimentos de turismo}

De acordo com a OMT (Organização Mundial do Turismo), enquanto o turismo cresce $7,5 \%$ ao ano, o crescimento da modalidade de turismo de natureza chega a $20 \%$ ao ano. Somente o turismo de natureza no início do século XXI representava 5\% do turismo mundial e a estimativa para o final da primeira década era de 10\% - tornando-se o segmento de turismo o de maior crescimento no mundo e com expressiva capacidade de geração de riquezas (Layrargues, 2004). De acordo com Mckercher (2002) inúmeros são os fatores responsáveis pelo crescimento do turismo de natureza, entre eles estão aspectos ligados ao maior interesse da população mundial pelas questões ambientais, anseio por um estilo de vida mais saudável e sustentável, busca de alternativas ao turismo tradicional de sol e mar, considerado de massa, e, portanto, predatório, em troca de um turismo que proporcione experiências personalizadas ou compartilhadas com grupos menores

É fato que o Brasil possui um enorme potencial para o desenvolvimento de atividades de turismo em ambientes naturais. Segundo o Estudo da Demanda Turística Internacional 2004-2008, $22,2 \%$ dos turistas internacionais que visitam o Brasil em busca de lazer tem como motivação principal para sua viagem o contato com a natureza (Mtur, 2010, p.31), ultrapassando inclusive o interesse pelo turismo cultural. Entretanto, a crescente demanda pelo contato com a natureza nem sempre se traduz ao crescimento de segmentos especializados em ofertar atividades em ambientes naturais.

O Diagnóstico do Turismo de Aventura no Brasil, lançado pela ABETA em 2009, ressalta que o mercado de turismo de aventura apresentou significativo crescimento da oferta, mas houve 
um decréscimo da demanda nos últimos anos, diferentemente, do que pode ser assistido na década de 90. De acordo com a pesquisa, o decréscimo varia de destino para destino, mas a percepção é de que esse quadro seja uma tendência do setor como um todo. Há três hipóteses para a redução da demanda. A primeira é "o enxugamento do volume de turistas e a conseqüente queda no faturamento, na opinião de alguns pesquisados, relaciona-se à queda do poder aquisitivo da população, em especial, da classe média" (ABETA, 2009, p.61). A segunda poderia ser a existência de amplo leque de Destinos de Turismo de Aventura, "cada um com suas peculiaridades de cenários e de atrativos naturais, além de existir uma gama maior de prestadores de serviço, o que acaba por pulverizar os lucros de cada empreendedor individualmente". Por último, considera-se o aspecto da imaturidade do setor como um dos motivos da queda de demanda e que, por isso, "o mercado consumidor ainda não expandiu em sua totalidade e de maneira uniforme" (ABETA, 2009, p.61).

Como em todo mercado, o turismo de aventura e o ecoturismo, cuja filosofia e prática deveriam ser predominantemente a oferta de produtos personalizados a pequenos grupos e com baixo impacto ambiental negativo, não está isento da busca da economia de escala, resultantes de grandes volumes de produção e da capacidade de atingir uma parcela maior da população dentro de um espectro mais amplo de faixa de renda em função da disponibilização do produto a um valor mais baixo.

Ressalta-se que a oferta de turismo de aventura e ecoturismo por grandes operadoras de turismo convencional é percebida como um problema por parte dos micro e pequenos operadores do setor, pela perda tanto da experiência do turista com a perda da essência do serviço prestado e da proposta de um contato com a natureza de forma consciente e sustentável. A comercialização de produtos para "grupos de maior dimensão e com roteiros e locais de visitação fixados e delimitados" diminuem a possibilidade do turista de ter um "contato espontâneo e aprofundado com a natureza, [que] passam a comprar a aventura como se esta fosse um item que está na moda" (ABETA, 2009, p.62)

Outro comportamento de algumas operadoras de grande porte é a sua capacidade de montar e levar a própria estrutura necessária para a realização das atividades, deixando de contratar a mão de obra local e reduzindo as possibilidades de interação do turista com a comunidade local. Por último, existe a pressão das grandes empresas sobre as pequenas agências receptivas locais para redução de custos dentro da economia de escala, repercutindo na queda de qualidade do serviço. Os empreendedores de turismo em ambientes naturais nos chamam a atenção para o fato de que "com a retenção de uma grande quantidade de clientes e sem todo o conhecimento necessário para lidar com o ambiente natural, as grandes operadoras acabam propiciando a monopolização do setor e, na percepção de alguns entrevistados, matando o destino" (ABETA, 2009, p.63).

Nesse sentido, de acordo com Layrargues (2004, p.3) as atividades de turismo na natureza tornam-se um "voraz consumidor de espaços, colocando-o à mercê do dilema econômico ecológico, caracterizado pelo balanço entre a maximização dos investimentos sem o comprometimento da capacidade suporte ideal". Assim sendo, ainda de acordo com o autor a sustentabilidade dos negócios 
de turismo na natureza dependem "em grande medida da capacidade de se encontrar esse ponto de equilíbrio" (Layrargues, 2004, p.03).

\section{0 processo de formalização das empresas - desafio dos empreendimentos de turismo}

O Diagnóstico do Turismo de Aventura no Brasil (ABETA, 2009) concluiu que a informalidade é grande vilã para o turismo. Sabemos que o nível de informalidade ainda é muito elevado, entretanto, essa condição parece estar sofrendo importantes modificações. Basta observar a adesão dos empreendimentos no Simples Nacional a partir de 2007, que passamos a ter conhecimento a partir dos avanços tributários no Brasil.

De acordo com a Receita Federal do Brasil já são mais de quatro milhões de empresas inscritas neste regime, que substitui o Simples Federal que contava apenas com cerca de 1,3 milhão de empresas. Segundo o ex-presidente do Sebrae, Paulo Okamotto, a superação da marca de 4 milhões de empresas no Simples Nacional comprova o acerto em se promover a simplificação, a desoneração e a formalização das micro e pequenas empresas por meio da Lei Geral.

Não obstante, a dinâmica de formalização da empresa individual também foi consolidada a partir da Lei Complementar 128/08 que criou a figura do microempreendedor individual, equiparada à pessoa jurídica para fins do Código Tributário Nacional. De maneira gratuita e pela internet, o empreendedor é capaz de se formalizar em menos de 10 (dez) minutos, obtendo instantaneamente o CNPJ, o NIRE e o seu alvará de funcionamento provisório.

Apesar da simplificação do processo de formalização destes empreendimentos como pessoas jurídicas, acompanhamos a posição de alguns órgãos públicos que parecem não ter acompanhado estes avanços. Tratando-se das atividades do profissional do guia de turismo, por exemplo, - Ministério do Turismo, a partir Ofício Circular N.․ 048/2010, que determinou que nada impede que o profissional "Guia de Turismo" se constitua como microempreendedor individual, passando a ser pessoa jurídica. Todavia, para o Ministério do Turismo, ele continua sendo pessoa física ao se cadastrar. Desse modo, perante este Ministério, o Guia de Turismo não faz jus às prerrogativas do microempreendedor individual.

Outro aspecto que interfere na formalização do setor do turismo é a própria falta de informação dos prestadores de serviços acerca do Cadastur, Sistema de Cadastro de pessoas físicas e jurídicas dos profissionais e negócios que atuam no setor de turismo. Este cadastro é administrado pelo Ministério do Turismo e foi estabelecido como obrigatório pela Lei Geral do Turismo para meios de hospedagem, agências de viagem, organizadoras de eventos, parques temáticos, acampamentos turísticos e guias de turismo ${ }^{7}$.

${ }^{7}$ Disponível em http://www.empresaformalturismolegal.com.br/categ/noticias. (Acesso em 15 de fevereiro de 2011) 
Esta informação sobre o desconhecimento dos prestadores de serviço foi verificado no levantamento realizado entre maio e junho de 2010 pelo programa Empresa Formal Turismo Legal ${ }^{8}$. Foram entrevistadas cerca de três mil pessoas das cinco regiões do Brasil e mais da metade desconhecia as leis, normas e regulamentos sobre a atividade do turismo. Dos trabalhadores e empresas selecionados para o levantamento, apenas $42 \%$ afirmaram conhecer as regras para atuar no setor.

Segundo Mckercher $(2002$, p.17) as empresas que atuam no segmento turismo de natureza possuem muitas semelhanças entre si, seja no "ponto de vista ético, operacional, de planejamento operacional, de desenvolvimento e distribuição de produtos". Consideramos em comum algumas características encontradas nas micro e pequenas empresas tais como, pequena equipe de gerenciamento, influência marcante do proprietário, posições de gerenciamento multifuncionais, sistemas de planejamento e controle informais inadequados, baixa capacidade de obter recursos financeiros, participação de mercado pouco significativas e dependência excessiva para poucos clientes, entre outras.

Pesquisa feita no com operadoras de ecoturismo no Canadá (Mckercher, 2002) descobriram que o seu mercado de turismo na natureza possui uma profusão de problemas de ordem empresarial, tais como: falta de planejamento empresarial; habilidades de marketing ingênuas ou insuficientes; pesquisa de mercado inadequada; problemas operacionais com fornecimento de produtos de baixa qualidade; problemas éticos ambientais e problemas de ordem pessoal geradas pela falta de experiência profissional e interpessoal dos jovens empreendedores, além de estafa física e mental gerada pelo acúmulo e intensidade de trabalho principalmente na alta temporada. Todos esses problemas podem afetar a qualidade dos produtos ofertados, contudo, a crescente demanda para consumo de roteiros de turismo em ambientes naturais tem como conseqüência, a exigência por parte dos consumidores de maior profissionalismo no setor, colocando em risco a confiabilidade nesse segmento de mercado.

Além dos problemas supracitadas, as empresas do setor de turismo, em particular o de natureza, enfrentam uma série de dificuldades de gerenciamento que contribuem para inibição da formalização ou falência empresarial, tais como operações ineficientes, isolamento comercial e social, subcapitalização, entre outras, a dizer das condições sazonais e transitórias, falta de consciência em relação à marca, concorrência acirrada de preços e criação de roteiros em lugares distantes dos principais mercados.

Paralelamente, um grande desafio do turismo de natureza está em estabelecer a inserção do trabalhador local no desenvolvimento do turismo em áreas naturais seria a partir da integração dos produtores artesanais na cadeia produtiva agroindustrial e na cadeia turística local. Isso "requer níveis de empreendedorismo no sentido de contribuir com a inclusão social e econômica deste segmento no mercado nacional e internacional. Para tal, se faz necessário, além dos recursos econômicos, uma boa dose de capital social" ${ }^{\prime \prime}$.

\footnotetext{
${ }^{8}$ Disponível em http://www.empresaformalturismolegal.com.br/categ/noticias. (Acesso em 15 de fevereiro de 2011) 
Se a formalização, para fins de desenvolvimento, se constitui ainda como um grande desafio para determinados empreendimentos no meio urbano, podemos afirmar que situação semeIhante se reproduz nas localidades rurais. Cabe afirmar que:

"... todos os atores têm papel fundamental em todas as fases do processo de desenvolvimento, como observar a singularidade local e regional na instalação de equipamentos e programas de qualificação profissional para gestão pública, privada e comunitária nos destinos"

(FRAGA, 2003 apud Mtur, 2010, p.16).

\section{Empreendimentos de apoio ao turismo em unidades de conservação}

Após a discussão sobre alguns pilares do desenvolvimento em empreendimentos de apoio ao turismo serão abordadas neste capítulo algumas questões que visam contribuir com o debate sobre a formalização e a prestação de serviços de apoio ao turismo em unidades de conservação. As questões que nos orientam são as seguintes: Como é estabelecido o processo de implementação de empreendimentos de apoio ao turismo em unidades de conservação? Quais são as barreiras e facilidades deste processo? Existem ações governamentais que favorecem a implementação de empreendimentos de diferentes portes em unidades de conservação?

De acordo com informações do Ministério do Meio Ambiente, o país abriga 310 (trezentas e dez) unidades de conservação federais e estima-se que 600 (seiscentas) unidades de gestão estadual e 700 (setecentas) de gestão municipal (GURGEL, et al. 2009). Estas áreas estão localizadas em diferentes biomas e propiciam a prática de diversas atividades aquáticas, aéreas e terrestres. O planejamento e a gestão do turismo nestas áreas depende de uma combinação de recursos físicos e financeiros para viabilizar a infraestrutura adequada para a visitação e, ao mesmo tempo, otimizar os efeitos positivos e minimizar os efeitos danosos da atividade sobre os bens naturais e culturais.

A diversificação de atrativos mostra de grande importância quando o produto é turismo em unidade de conservação. Esse fato é demonstrado no Estudo sobre o Turismo Praticado em Ambientes Naturais Conservados, que contemplou 31 (trinta e uma) operadoras de turismo nas cidades em São Paulo/SP, Rio de Janeiro/RJ, Belo Horizonte/ MG e Brasília/DF e 6 (seis) mil turistas nos ajuda a conhecer melhor a demanda do turismo em ambientes naturais. Segundo análise: 
Apesar de $42 \%$ dos turistas destacarem que a motivação principal para a viagem era a visita a unidade de conservação, é frequente observar que os turistas também realizavam outras atividades na região. A permanência média das viagens em visita às Áreas Conservadas era de 5,5 dias, sendo 2,3 dias destinados exclusivamente a elas e 3,2 dias a outros motivos. Convém ressaltar que quando havia outros tipos de motivação, o tempo de permanência era maior. Assim, é possível observar a importância e oportunidade de diversificação de atividades no entorno de uma unidade de conservação. A distância destas áreas, suas extensões, facilidade de acesso e, principalmente, os produtos ofertados dentro e fora da unidade, se relacionam ao tempo de permanência na área. O gasto médio da viagem também não se restringe apenas a visitação à unidade, mas também a gastos na cidade e na região da unidade. (Mtur, 2010, p.37)

No entanto, é importante salientar que o planejamento e a gestão destas atividades ultrapassam as questões relacionadas à segmentação do mercado, fazendo emergir questões como a parceria entre as esferas pública e privada no desenvolvimento do turismo em áreas protegidas (RODRIGUES, 2009), tema que será tratado mais adiante no presente artigo.

Podemos citar um exemplo de esforço de formalização de empreendimentos de turismo em áreas naturais a Associação Brasileira de Turismo de Aventura - ABETA fundada em 2003, por um pequeno grupo de empresários e especialistas do turismo de aventura, que já buscava uma mobilização por meio de um fórum de discussão virtual. A organização surgiu em meio à um complexo e rico debate sobre o crescimento do turismo de aventura no país, que trouxe à tona questões importantes como a segurança na realização das atividades, a qualidade dos equipamentos utilizados, a capacitação profissional, o manejo dos impactos socioambientais da atividade, as parcerias com a esfera pública para o planejamento e a gestão das atividades em ambientes naturais, entre outras.

Até janeiro de 2011 a associação contava com 307 associados, de diversas regiões do país. Com o apoio do Ministério do Turismo, que priorizou em sua política a qualificação e a segurança no turismo de aventura, a ABETA tornou-se a entidade executora do "Programa Aventura Segura", que visa à estruturação, à qualificação e ao fortalecimento do Ecoturismo e do Turismo de Aventura no Brasil. Este programa foi desenvolvido em parceria com o Sebrae/Na e abrangeu 16 destinos de 13 estados brasileiros, mobilizando empreendedores de 100 municípios. Mas, qual seria o diferencial das empresas associadas à ABETA? O que trouxeram de inovação no âmbito de desenvolvimento do turismo em ambientes naturais?

As pesquisas sobre o ecoturismo e o turismo de aventura relacionam estas atividades ao viés do "turismo alternativo", que surgiu como contraponto ao turismo de massa, tradicional (PIRES, 
2002). O fato do turismo em ambientes naturais emergir como uma alternativa ao modelo de turismo de larga escala que é depredador, engendra alguns aspectos inovadores nas práticas adotadas pelos empreendedores que atuam nestas áreas (RODRIGUES, 2009).

O turismo praticado em unidades de conservação pressupõe a responsabilidade ambiental, social e cultural frente aos destinos e às comunidades receptoras. Neste sentido, empreender significa desenvolver algo novo, criar novos produtos, encarar desafios, considerando um cenário específico de atuação. No caso do ecoturismo e do turismo de aventura, esse cenário evoca atitudes e responsabilidades intrínsecas às atividades, uma vez que se sustentam em atrativos e áreas naturais e culturais frágeis, que possuem características especiais de proteção. Ao incorporar em suas práticas os critérios de responsabilidade ambiental e social, as empresas buscam conquistar novos clientes e formatar novos produtos. Assim, a inovação caminha em sintonia com a responsabilidade socioambiental, tema que vem assumindo um papel cada vez mais criterioso no âmbito empresarial (RODRIGUES, 2009).

A evolução do conceito de responsabilidade socioambiental na rotina das empresas acompanhou o processo de mobilização em diversos setores econômicos em torno da questão ambiental, intensificado a partir da década de 1990. No Brasil, em 1998, com a aprovação da Lei de Crimes Ambientais, a pessoa jurídica tornou-se passível de indiciamento criminal por danos ambientais. Isso gerou uma maior responsabilização das empresas e trouxe à tona os elementos da cadeia produtiva, do tratamento da matéria-prima até o descarte dos resíduos (KISHINAME et al., 2002).

Um rápido levantamento realizado por Kishiname et al. (2002) entre 100 empresas afiliadas ao Instituto thos $^{10}$ de responsabilidade socioambiental apontou cinco tipos de atividades que estão sendo desenvolvidas por elas na linha da responsabilidade socioambiental: agregar valor à sustentabilidade; buscar ecoeficiência; atuar no ciclo de vida do produto; fazer investimento social; promover a educação ambiental.

O Instituto Ethos estabelece sete diretrizes que devem ser observadas na gestão socialmente responsável das empresas: valores, transparência e governança; público interno - funcionários das empresas-; meio ambiente; fornecedores; consumidores e clientes; comunidade; governo e sociedade.

Com base nestas diretrizes, a Associação Brasileira de Empresário de Ecoturismo e Turismo de Aventura (ABETA, 2008) elaborou um questionário para avaliar as práticas socioambientais nas empresas de ecoturismo e no turismo de aventura. Participaram da pesquisa 121 empresas associadas e $52 \%$ desenvolvem seus produtos turísticos em unidades de conservação sejam elas públicas ou privadas. A pesquisa contemplou algumas questões para avaliar o grau de envolvimento das empresas em atividades de conservação ambiental. Das empresas que participaram da pesquisa,

\footnotetext{
${ }^{10} \mathrm{O}$ Instituto Ethos de Empresas e Responsabilidade Social foi criado em 1998 por um grupo de empresários e executivos com o objetivo de mobilizar, sensibilizar e ajudar as empresas a gerir seus negócios de forma socialmente e ambientalmente responsável. É uma OSCIP, com mais de 1.300 empresas associadas, que têm faturamento anual de aproximadamente 35\% do PIB brasileiro e empregam cerca de 2 milhões de pessoas.
} 
42\% participam de programas de proteção de áreas naturais, 47\% participam de comitês ambientais e 27\% integram os conselhos gestores de unidades de conservação.

Sinalizadas as necessidades de criação de certos valores coletivos citados no parágrafo acima, parece ser imprescindível a existência de políticas públicas norteadoras que indiquem a criação de um ambiente propício a proliferação destas práticas. As políticas nacionais devem ser desenvolvidas de forma participativa e democrática, visando estimular o desenvolvimento de talentos empreendedores locais. Seguindo a tendência mundial de descentralização e valorização de estâncias de governança, a liderança local deve ocupar papel relevante na promoção do desenvolvimento econômico e social, de um determinado território.

O conceito de "local" adquire a conotação de "alvo" sócio-territorial das ações. Trata-se de uma nova dinâmica sócio-econômica capaz de, a partir do local de encontro de ações do Estado e da sociedade, independente do seu tamanho, potencializar resultados em virtude das parcerias inter-institucionais que ali podem ser mais facilmente celebradas e da convergência e integração das políticas e dos programas que acabam co-incidindo (BRASIL, 1998, p.6).

Além do crescimento econômico, o desenvolvimento passa a ser entendido de uma forma bem mais ampla englobando as dimensões ambiental, social, econômica, política, institucional, ética, humanística e cultural. Os atores e empreendedores locais assumem papel diferenciado e altamente relevante no contexto da sustentabilidade, o que pode ser um fator determinante e facilitador na concessão de serviços de apoio ao turismo em áreas naturais.

As lideranças locais são capazes de identificar problemas e necessidades pertinentes a sua comunidade e conseqüentemente podem propor soluções adequadas, considerando as potencialidades locais e as habilidades existentes. De acordo com Fischer (2002, p.19):

"o processo de desenvolvimento é mobilizado por organizações que trabalham juntas ou por interorganizações cuja principal característica é a hibridização ou a complexidade. As interorganizações são constituídas por organizações diferenciadas, conectadas por propósitos comuns, isto é, integradas".

Não há homogeneidade nas interorganizações, pois, os componentes mantêm diferentes papéis sociais, níveis de responsabilidade e bases de poder em uma interação dinâmica. Os objetivos desse conjunto de organizações diferenciadas são voltados para a promoção do desenvolvimento local podendo ser complementares, superpostos ou conflitantes. Os grupos "se articulam e se opõem em torno de interesses comuns" (FISCHER, 2002, p.14) e essa articulação, construída 
sobre a ação de diferentes atores individuais e coletivos, constitui a noção de poder local, pressupondo uma capacidade de agir em bases plurais.

É certo que o desenvolvimento local exige a participação e o engajamento do poder público, das empresas e das organizações da sociedade civil num modelo de gestão integrada de políticas públicas de forma articulada entre as diversas instâncias (federal, estadual e municipal) e áreas de governo. Trata-se de novos mecanismos que exercitem o novo paradigma da relação entre Estado e Sociedade (articulação, descentralização, parceria, transparência, controle social, participação). "Já não se trata mais de escolher entre o Estado e o privado, entre o social e o econômico. O conceito-chave não é escolha e sim articulação" (DOWBOR, 1999, p.5).

"Nem as macroestruturas do poder estatal nem as macroestruturas do poder privado responderão às necessidades prosaicas da sociedade em termos de qualidade de vida, de respeito ao meio ambiente,

de geração de um clima de segurança, de preservação do espaço de liberdade e de criatividade individual e social. A palavra-chave, aqui, é evidentemente a articulação dos três elementos do triângulo. Somos condenados a articular de maneira razoavelmente equilibrada os poderes do Estado, das empresas privadas e das organizações da sociedade civil (DOWBOR, 1999, p.8)."

\section{A esfera pública e privada na promoção do turismo em unidades de conservação}

Para que as unidades de conservação, sobretudo os parques, cumpram uma de suas funções, a de promover a visitação, com fins de educação e interpretação ambiental, recreação e turismo em contato com a natureza, é necessário estruturar os serviços correspondentes ao suporte físico e logístico para a realização destas atividades. A prestação destes serviços pode-se dar de maneira direta, quando é fornecida pelo próprio Estado, ou indireta, quando o Estado a delega a particulares ${ }^{11}$. A transferência de certos serviços a terceiros é defendida como uma forma de potencializar, de maneira sustentável, o aproveitamento dos recursos da unidade de conservação, ao mesmo tempo em que canaliza os esforços dos órgãos responsáveis pela administração destas áreas para atividades como controle, fiscalização e proteção dos recursos naturais (RODRIGUES, 2009).

\footnotetext{
"O Decreto n4.340, de 22 de agosto de 2002, que regulamenta artigos da Lei n9.985, de 18 de julho de 2000, dedicou o Capítulo VII ao tema da autorização para a exploração de bens e serviços em UC. O Art. 25 dispõe que "é passível de autorização a exploração de produtos, subprodutos ou serviços inerentes às unidades de conservação, de acordo com os objetivos de cada categoria de unidade". Os produtos e serviços característicos das unidades de conservação serão abordados, no caso específico do tema desta pesquisa, como "aqueles destinados a dar suporte físico e logístico à implementação das atividades de uso comum do público, tais como visitação, recreação e turismo" (Parágrafo único, inciso l, Art. 25 da Lei 9.985, de 18 de julho de 2000).
} 
Kramer et al. (2002), ao analisarem o papel da iniciativa privada no manejo das áreas protegidas, afirmam que a "privatização da conservação" pode assumir várias formas, desde contratos para prover serviços específicos, como alimentação e alojamento, até parcerias público-privadas para o manejo dos parques nacionais. O papel da iniciativa privada foi analisado de maneira ampla pelos autores, incluindo áreas privadas e áreas manejadas por organizações não-governamentais. Embora os estudos de caso analisados pelos autores apresentem realidades distintas, em termos legais e institucionais, da realidade dos parques nacionais brasileiros, é pertinente abordar o espectro de organizações identificadas como possíveis "parceiras" na gestão de áreas protegidas.

O espectro apresenta, de um lado, as agências estatais, e no outro extremo as organizações privadas com fins lucrativos. Entre estas duas instâncias, encontram-se as agências paraestatais, autoridades encarregadas de parques que se beneficiem de certo grau de independência; organizações de interesse; comunidades e pequenos grupos de indivíduos; e as organizações privadas sem fins lucrativos. O termo parceiras foi utilizado para reforçar que, no caso dos parques nacionais, a posse e o domínio da área são públicos, sendo incentivada a gestão integrada com outras instituições para os serviços de apoio à visitação, as funções administrativas, o apoio à pesquisa, entre outras (RODRIGUES, 2009).

A parceria entre os setores público e privado pode ser entendida no sentido amplo para abranger as várias "modalidades de ajustes" entre essas instâncias na consecução de objetivos comuns (DI PIETRO, 2005, p. 21). Independentemente da "modalidade de ajuste" escolhida (concessão, permissão, autorização, parceria com OSCIP), os princípios que orientam a prestação de serviço público adequado (regularidade, continuidade, eficiência, segurança, atualidade, generalidade, cortesia, modicidade das tarifas ${ }^{12}[18]$ ) aportam reflexões constantes sobre o papel do público e do privado. Ainda que os serviços de apoio à visitação nos parques não sejam considerados 'serviços públicos' no sentido estrito, a aplicação subsidiária dos princípios do serviço adequado pode orientar, em certa medida, a prestação deles em áreas de domínio público (RODRIGUES, 2009).

Ao delegar a prestação de serviços a terceiros, o Estado requer que o serviço seja prestado com qualidade, segurança e com menor impacto sobre os recursos envolvidos - ambientais, sociais, culturais. Por se tratar de uma unidade de conservação, a prestação de serviços de apoio à visitação pressupõe a adoção de critérios ambientais condizentes com os objetivos da área e com os princípios fundamentais do Direito Ambiental. Neste contexto, é interessante ressaltar a análise de Kishiname et al. (2002) sobre a gestão do ecoturismo que, de certa forma, induz uma perspectiva empreendedora no âmbito das iniciativas em unidades de conservação:

\footnotetext{
${ }^{12}$ A Lei 8.987, de 13 de fevereiro de 1995, também conhecida como a "Lei de Concessões", dispõe sobre as características do "serviço adequado" no âmbito da prestação de serviços públicos por meio de contratos de concessão.
} 
Ao contrário do turismo tradicional, as diferentes modalidades de ecoturismo privilegiam o chamado empreendedorismo, pelo fato de demandarem, na ponta da execução dos serviços, a presença de pessoas altamente qualificadas, que estabelecem e gerenciam as atividades dos turistas junto às comunidades locais, áreas de preservação públicas ou privadas e áreas de recreação (p. 392).

O depoimento acima evoca a responsabilidade dos atores envolvidos no turismo em unidades de conservação. Nesta linha, pode-se dizer que o empreendedor de um serviço de apoio à visitação nos parques nacionais vai além de mero prestador de serviço. A prestação de serviços nestas áreas pode aportar significados, principalmente ambientais e culturais, que a diferencia da prestação do mesmo serviço no ambiente urbano, em um parque temático ou shopping. Esta perspectiva nos remete ao empreendedor como um agente social situado e atento ao contexto socioeconômico e ambiental local (RODRIGUES, 2009).

O empreendedor em unidade de conservação deve atuar como um empreendedor "situado" preconiza as raízes locais e não a "simples exportação de um vulgar sistema econômico de um espaço para o outro" (ZAOUAL, 2006, p. 23). Assim, o sentido de comprometimento com o local é uma característica essencial para o empreendedor situado. Esta abordagem se baseia na "teoria dos sítios simbólicos", disseminada por Zaoaul, que compreende que "tal como a mão invisível do mercado, o sítio é uma estrutura imaginária de coordenação econômica e social, mas ele associa instantaneamente as duas dimensões, contrariamente ao mercado" (p.18). No ponto de vista do autor, os "sítios simbólicos de pertencimento" são mais intensos que o mercado, pois portam uma pluralidade de modos de coordenação tais como: dádiva, solidariedade, reciprocidade, cooperação, aprendizagem recíproca, os quais representam verdadeiros enigmas científicos, inclusive entre os economistas. Neste sentido, a lógica dos sítios simbólicos de pertencimento sugere a reapropriação e a ressignificação das categorias usuais como mercado, concorrência, preço, lucro, produção, com base nas crenças e práticas locais.

O pensamento dos sítios é uma maneira de repensar os "lugares" em sua especificidade, levando em conta o sistema de representação dos atores. Os sítios não são aqueles "não-lugares" semelhantes às grandes estações ferroviárias ou a supermercados da mega-máquina da sociedade econômica (ZAOAUL, 2006, p. 32).

Zaoaul (2006) reforça a importância do comprometimento dos membros de uma organização, que parece óbvia, mas que no dia-a-dia acaba se perdendo em função da busca primordial pelo lucro. Argumenta que a eficácia de uma organização depende diretamente do "sentido investido por seus membros em seus objetivos" (2006, p. 43). Seguindo esta perspectiva, cabe perguntar qual é o sentido investido na atuação dos empreendedores nas unidades de conservação? Estes atores se 
identificam com alguma atividade específica - mergulho, rafting, escalada - e com as características naturais e culturais locais? Como lidam com os efeitos socioeconômicos e ambientais do turismo no local?

\section{0 Caso llustrativo}

Como forma de ilustrar a discussão da perspectiva macro, estrutural que construímos até aqui e que enfoca fatores ambientais, sociais e econômicos de uma determinada sociedade em uma época e introduzir uma perspectiva micro ao processo do empreendedorismo, isto é, a perspectiva que enfoca o comportamento, competências e habilidades dos indivíduos, será apresentada uma experiência de turismo em ambientes naturais na cidade do Rio de Janeiro. A empresa Lagoa Aventuras, que está situada no Parque Natural Municipal da Catacumba'³, na Lagoa. O levantamento primário de informações foi realizado a partir de janeiro de 2011, e baseou-se em entrevista com um dos sócios do empreendimento, conversas informais com os sócios gestores do empreendimento, observação de campo e pesquisa via Internet.

\subsection{O Empreendimento: Lagoa Aventuras}

A empresa Lagoa Aventuras começou a funcionar em março de 2010, após o processo de formalização junto à prefeitura da cidade do Rio de Janeiro, responsável pela administração do Parque Natural Municipal da Catacumba. O empreendimento está localizado na área reflorestada do parque de 31 hectares. Este empreendimento é o primeiro "Circuito de Aventuras" situado em uma unidade de conservação na cidade do Rio de Janeiro, e oferece cinco atividades de aventura para turistas e visitantes.

Entre os equipamentos instalados no "Circuito de Aventuras" estão uma tirolesa ${ }^{14}$ - cabo aéreo ancorado entre dois pontos, pelo qual o aventureiro se desloca preso a roldanas; circuito de arvorismo ${ }^{15}$ - passagens aéreas nas copas das árvores, fixadas em troncos de eucalipto e com nove estágios de dificuldade; e adaptações para rapel num paredão de 90 na Pedra do Urubu, no cume do parque, com cinqüenta metros de altura.

\footnotetext{
${ }^{13}$ Segundo informações do site oficial do parque este foi construído onde ficava uma favela, removida nos anos 60 do século XX. o Parque da Catacumba é o resultado da execução de dois projetos notáveis: na parte baixa, até a meia encosta do morro, uma sólida obra de arquitetura, ajardinamento e paisagismo criou no local um espaço suntuoso e agradável, formado por alamedas, praças e jardins, com muitas árvores, e uma exposição ao ar livre de esculturas de artistas famosos. Em um outro momento, da meia encosta ao alto do morro, foi feito o reflorestamento, com a predominância de espécies encontradas na mata atlântica. Em conseqüência, surgiu a fauna local, formada em sua maior parte por pássaros e sagüís. Uma trilha leva ao ponto mais alto do morro, onde um mirante permite apreciar uma das mais belas vistas da Lagoa Rodrigo de Freitas.

${ }^{14}$ A tirolesa tem 75 metros e atravessa a parte baixa do parque. O muro de escaladas artificial tem sete metros de altura e oferece três vias com inclinações diferentes, proporcionando assim vias com diferentes graduações.

${ }^{15} \mathrm{O}$ circuito de arvorismo fica a seis metros do chão, tem 120 metros de comprimento e oferece nove brinquedos diferentes que desenvolvem coragem, equilíbrio e atitude. Há também um circuito para crianças, que fica a 1 metro do chão e tem 65 metros de comprimento e cinco brinquedos diferentes.
} 
A empresa fornece aos visitantes guias que, além de orientar os visitantes, transmitem informações sobre educação ambiental e consta de um stand com informações sobre passeios e roteiros de aventura. Além das atividades previstas para aventura propriamente dita, existe a oferta do espaço para realização de festas, colônia de férias, eventos corporativos e educação ambiental.

O projeto nasceu da iniciativa do carioca Gabriel Werneck, 29 anos, que possui um histórico de atividades em natureza. Aos 14 anos, ganhou de sua mãe um curso de escalada e, aos 18, pedalava e fazia remo, além de outros esportes que envolvessem aventura. Ele afirma ter sempre gostado de fazer trilhas la à Floresta da Tijuca, subia o Pão de Açúcar. Em 1999, morou nos Estados Unidos e quando voltou começou a levar os turistas nesses lugares que já tinha alguma familiaridade. Foi assim que surgiu a primeira empresa de Werneck, a agência de turismo de aventura Rio Hiking, operadora pioneira de ecoturismo e turismo de aventura. Atualmente a empresa tem vinte roteiros no Estado do Rio de Janeiro, além de pacotes para diversos destinos ecológicos do Brasil, alcançando cerca de 80 saídas por mês. A Rio Hiking é a primeira empresa no Estado do Rio de Janeiro, e está entre as trinta e cinco primeiras no Brasil, a receber a Certificação no Sistema de Gestão de Segurança (SGS), em conformidade com a norma técnica ABNT NBR 15331.

Depois de cursar a faculdade de turismo e fazer pós-graduação em administração de empresas, Werneck partiu para seu desafio seguinte: a implementação da empresa Lagoa Aventuras. Este afirma que já tinha a idéia do parque quando procurou o Marcelo Skaf, então dono da Cânion Iguaçu, para tirar umas dúvidas. Hoje em dia são sócios.

O sócio e diretor Marcelo Skaf, também consultor de planejamento ambiental, foi sócio e fundador da Canion Iguaçu, a primeira empresa a ter a concessão no Brasil para a exploração de turismo de aventura em unidades de conservação, dentro do Parque Nacional do Iguaçu. Skaf viu esse potencial no Rio de Janeiro pois, segundo ele havia o desejo do município em criar um parque com esse formato, principalmente por conta da Copa e Olimpíadas. Assim que saiu o edital eles concorreram à licitação e venceram

Para Skaf, a localização foi uma questão importante para pensar. O cidadão não percebia o espaço do Parque da Catacumba, como seu e, por isso, não dava o valor devido. Além disso, é importante ter um tipo de ambiente como esse em um lugar acessível". Sobre a importância do turismo de aventura, Skaf enfatiza que o conhecimento de um novo ambiente através da interação com a natureza tem de acontecer de forma segura tanto para quem pratica, quanto para o Parque. Ainda como atrativo as atividades apresentam-se como lúdicas ao enfrentar os desafios. A autorização para operação no Parque foi concedida em 2009 após licitação pública da secretaria Municipal do Meio Ambiente.

Gabriel Werneck além de ser sócio e diretor desde 1999 da empresa Rio Hiking, ele é também sócio da Rio Pass, empresa de Tecnologia na área de turismo, que beneficia os usuários com um cartão exclusivo para turistas estrangeiros, nos moldes dos city cards vendidos nas principais capitais 
do mundo; dedicou-se ao desenvolvimento de novos empreendimentos, participou da fundação da ACTA (Associação Carioca de Turismo e Aventura), está envolvido em um projeto social de turismo desde Março de 2007, o Santa Teresa Tour, onde organiza e desenvolve a visitação turística com participação da comunidade local e utiliza o patrimônio turístico local de forma sustentável.

O também sócio e diretor Rafael Ribeiro é também sócio e fundador da Inside Rio, maior operadora de turismo receptivo focada em jovens no Rio de Janeiro. A empresa tem como missão atender aos desejos e necessidades dos viajantes que buscam intercâmbio cultural e diversão em seus roteiros. A empresa adotou diferenciais para atender seu público específico. Sabendo, por exemplo, que jovens gostam da noite, os passeios só começam a partir das 13 horas, com tempo para almoçar no albergue e economizar. Nas visitas às atrações tradicionais, como o Cristo Redentor, mais do que a história do monumento, os pontos fortes são a localização das praias mais famosas ou do Maracanã. Para reforçar este vínculo, outro diferencial da operadora é que todos os guias são estudantes. A idade é importante ainda para agüentar o pique dos clientes nas caminhadas pela floresta da Tijuca ou nos bailes do Salgueiro, que varam a madrugada com muito hiphop, funk e samba.

A Lagoa Aventuras conta ainda com a pareceria de empresas como Biruta Mídias Mirabolantes (marketing e publicidade), Ferrino (soluções em atividades verticais) e Trema (design), além da ABETA e da Prefeitura do Rio de Janeiro. Segundo Gabriel Werneck, eles pretendem trabalhar em parceria também com outras empresas. Além disso, foi a primeira empresa a divulgar e vender seus serviços através de sites de compras coletivas, tendo participado da estréia do site pioneiro no Brasil: o Peixe Urbano.

Os empreendedores da Lagoa Aventuras está atenta ao mercado criando novos produtos turísticos para serem ofertados aos seus clientes. Um bom exemplo pode ser observado na temporada de verão de 2011 houve a implantação do Espaço "Arena Lagoa Aventuras" no Shopping New York City Center na Barra da Tijuca, Rio de Janeiro. A empresa objetiva desta maneira crescer e continuar a prestar bons serviços na segmentação de turismo de aventuras. Segundo Gabriel este quer continuar esse ritmo de trabalho por mais alguns anos, e contribuir para fazer do Rio de Janeiro a capital mundial do turismo de aventuras.

\subsection{Aspectos da Dimensão Micro}

A partir da descrição acima podemos identificar algumas características micro no processo de empreendedorismo, aquelas que enfocam o comportamento, as competências e habilidades dos indivíduos. Isto porque, a partir do seu gosto e experiência em atividades esportivas em ambientes naturais um de seus sócios, Gabriel Werneck iniciou informalmente levando turistas para atividades tais como trilhas, escaladas, raftings. Com o tempo o seu negócio foi crescendo e este se formalizou. Após capacitação em gestão e em turismo, sua pós-graduação e sua graduação, Werneck estava 
motivado a se lançar em um novo empreendimento e procurou informação em outra experiência aparentemente com as mesmas características, a Cannion Iguaçu de Marcelo Skaf, situada no parque nacional de Foz do Iguaçu. Este se tornou sócio do empreendimento Lagoa Aventura.

Destacamos ainda a importância dada por Skaf no processo de implementação do negócio a importância do lugar, isto devido ao fácil acesso do turista por estar na área metropolitana da cidade, mais exatamente na zona sul do Rio de Janeiro na confluência entre Copacabana e Ipanema. A questão paisagística do parque deve também ser levado em consideração, tendo este dois ambientes integrados: a galeria de esculturas ao ar livre e uma área reflorestada com espécies de flora e fauna da mata atlântica. Os pontos positivos do lugar conta ainda com uma vista espetacular da Lagoa Rodrigo de Freitas.

Os empreendedores afirmam que sabiam do interesse da prefeitura em realizar alguma atividade de revitalização do espaço do Parque da Catacumba. Eles tinham um produto estruturado, com um foco lúdico e educativo, sintonizado com as tendências do mercado do turismo em áreas naturais, aprovavam o local e já tinham tido experiência com a parceria público e privado, com o Cannion Iguaçu. Assim ganharam a licitação pública.

Seus sócios atuam também com outros produtos no setor turístico que envolvem o mesmo segmento e se articulam no trade turístico tais como: agência de tour de aventura, city cards, operadora de turismo para jovens estudantes. Seus outros parceiros são da área de marketing, equipamentos e soluções para a atividade, tais como: escaladas, rappel, design; a ABETA e a prefeitura do Rio de Janeiro. Eles são receptivos com a possibilidade de novas parcerias. Sempre atuando de maneira pioneira foram inovadores ao terem sido um dos primeiros clientes do Peixe Urbano, ou seja, do primeiro site brasileiro de vendas na rede social. Eles estão atentos a novos empreendimentos que estejam sintonizados com as atividades esportivas de aventura e do turismo em ambientes naturais, tal como o espaço de escalada no shopping da Barra da Tijuca, agregando cada vez mais valor a sua marca.

Desta maneira podemos observar que apesar das condições macro serem estruturantes do processo de empreendedorismo e mesmo sendo elas favoráveis ao empreendimento, estas não garantem o sucesso do mesmo. Para criar melhores condições de obter este sucesso observa-se que é necessário a articulação destas condições macro com as condicionantes micro apresentadas no decorrer das etapas do processo empreendedor.

\section{Considerações Finais}

A perspectiva micro, que enfoca o comportamento, competências e habilidades dos indivíduos, quanto uma perspectiva macro que enfoca fatores ambientais, sociais e econômicos de 
uma determinada sociedade, são ambas importantes para propiciar o entendimento da complexidade intrínseca ao processo empreendedor. A perspectiva macro aborda fatores ambientais referentes às variáveis econômicas, financeiras e política do país ou da região. Esses fatores geralmente extrapolam o controle do empreendedor, entretanto, servem de parâmetros para a tomada de decisões. Já a perspectiva micro adota uma abordagem centrada no indivíduo com relação ao seu comportamento e valores ou no grupo de pessoas envolvidas e suas relações tal como: sócios, parceiros, investidores, clientes.

Em cada fase do processo empreendedor, a dizer o reconhecimento de uma oportunidade, os avanços, a implementação e a gestão para o crescimento estão presentes características micro, mas também das variáveis de nível macro, ambas contribuem para a dinâmica dos acontecimentos. Na perspectiva macro o empreendedor não possui gerência sobre eles, enquanto na micro este é o sujeito da ação.

Como características da dimensão micro, dos fatores internos da dinâmica do processo, os fatores do empreendedor tais como: energia, disposição de correr riscos, autoconfiança, educação, experiência profissional. Com relação aos fatores ainda micro com o referencial do empreendedor estariam as condições do meio social do agente que seriam: o incentivo de amigos, familiares, a vivencia em ambientes empreendedores, entre outros. No aspecto macro da dimensão político/ econômico, social, dos fatores externos temos como exemplo a legislação, as políticas públicas, a concorrência, a recursos governamentais. Esses fatores individuais e sociais influenciam todas as fases do processo. Porém são nas interseções entre as oportunidades valiosas e indivíduos empreendedores que se encontra a dinâmica de construção do empreendedorismo.

Quanto aos fatores macros do turismo em áreas naturais existe o fato deste ter crescido no mundo e também no Brasil. O trade turístico e em especial o de áreas naturais é constituído de micro empresários na sua maioria informais que trabalham localmente. Porém a competitividade entre destinos e a entrada no mercado por empresas de médio e grande porte, tem gerado mais degradação ao meio ambiente e falta de comprometimento dos princípios fundamentais de sustentabilidade do turismo em áreas naturais. A entradas das grandes corporações, mas também a informalidade dos pequenos empresários contribuem fortemente para perda da qualidade do produto. Esses fatores tem forçado a por parte dos empresários uma revisão da maneira de trabalhar.

A simplificação dos tramites legais e burocráticos para a formalização dos micro empresários tem sido parte da política federal nos últimos anos, mas com relação ao turismo ainda faltam muitos esclarecimentos e aperfeiçoamentos, além de maior difusão no setor turístico para que seja mais utilizado de maneira mais efetiva.

No caso do turismo de áreas naturais existe ainda uma exigência de um maior profissionalismo devido aos cuidados com a sustentabilidade, além de enfrentarem uma série de problemas de gerenciamento, tais como operações ineficientes, isolamento comercial e social, 
subcapitalização, entre outras e de operacionalização, a dizer, condições sazonais e transitórias, falta de consciência em relação à marca, concorrência acirrada de preços e lugares distantes dos principais mercados, descaso com a segurança, etc., que contribuem para inibição da formalização ou falência empresarial.

A ABETA é uma entidade sem fins lucrativos, parceira, que busca a melhoria da qualidade dos serviços do turismo em áreas naturais, em especial do turismo de aventura tratando de temas como: segurança na realização das atividades, a qualidade dos equipamentos utilizados, a capacitação profissional, o manejo dos impactos socioambientais da atividade, as parcerias com a esfera pública para o planejamento e a gestão das atividades em ambientes naturais, entre outras.

No turismo praticado em unidades de conservação, mais fortemente do que em qualquer outro local pressupõe a responsabilidade ambiental, social e cultural frente aos destinos e às comunidades receptoras. Neste sentido, empreender significa desenvolver algo novo, criar novos produtos, encarar desafios, considerando um cenário específico de atuação. Assim, nesta situação de turismo em áreas naturais a inovação caminha em sintonia com a responsabilidade socioambiental, tema que vem assumindo um papel cada vez mais criterioso no âmbito empresarial,

Parece ser imprescindível a existência de políticas públicas norteadoras que indiquem a criação de um ambiente propício a proliferação destas práticas. As políticas nacionais devem ser desenvolvidas de forma participativa e democrática, visando estimular o desenvolvimento de talentos empreendedores locais. Seguindo a tendência mundial de descentralização e valorização de estâncias de governança, a liderança local deve ocupar papel relevante na promoção do desenvolvimento econômico e social, de um determinado território.

As parcerias parecem ser ainda mais necessárias no turismo, especialmente nas unidades de conservação, sobretudo nos parques; para que estes cumpram suas funções, de promover a visitação, com fins de educação e interpretação ambiental, recreação e turismo em contato com a natureza, sendo necessário estruturar os serviços correspondentes ao suporte físico e logístico para a realização destas atividades. A prestação destes serviços pode-se dar de maneira direta, quando é fornecida pelo próprio Estado, ou indireta, quando o Estado a delega a particulares. Por se tratar de uma unidade de conservação, a prestação de serviços de apoio à visitação pressupõe a adoção de critérios ambientais condizentes com os objetivos da área e com os princípios fundamentais do Direito Ambiental.

Por sua vez a características micro no processo de empreendedorismo, aquelas que enfocam o comportamento, as competências e habilidades dos indivíduos, foram identificadas nos relatos dos sócios da Lagoa Aventuras manifestas no gosto e prática de atividades esportivas em ambientes naturais de Werneck, passando pela informalidade e então pela formalização, sendo necessária a etapa de maior capacitação, a energia para buscar informação sobre outra experiência aparentemente com as mesmas características do seu novo projeto, foi quando conheceu 
seu sócio Skaf. Eles tinham um produto estruturado, com um foco lúdico e educativo, sintonizado com as tendências do mercado do turismo em áreas naturais, aprovavam o local e já tinham tido experiência com a parceria público e privado, com o Cannion Iguaçu. A importância dada por Skaf no processo de implementação do negócio ao lugar , do conhecimento prévio do interesse da prefeitura em realizar alguma atividade de revitalização do Parque da Catacumba. Essas articulações, interesse e entusiasmo ajudaram a ganharam a licitação pública.

Assim, com relação ao turismo em unidades de conservação estes por um lado devem estar sintonizados com as tendências internacionais do turismo em áreas naturais e pela lógica do mercado turístico, porém possui pressupostos específicos da atividade com bases na responsabilidade sócio-ambiental. Nestes casos o trabalho em parceria setor público e privado faz-se imprescindível. A formalização e a prestação de serviços de apoio ao turismo em áreas naturais depende de uma composição de fatores que visam aprimorar a qualidade do serviço prestado e ampliar as alternativas para a inserção socioeconômica dos atores locais, com ênfase nos micro e pequenos empreendimentos.

A construção do percurso do empreendedor e do empreendimento acontece de maneira diferente de caso a caso pois depende da interação entre as dimensões macro e micro do processo. O sucesso ou o fracasso não vai depender de elementos isolados, unívocos, mas sim da combinação de vários elementos de conjunturas externas e internas a cada etapa do negócio.

\section{Referências bibliográficas}

\section{ABETA - ASSOCIAÇÃO BRASILEIRA DAS EMPRESAS DE ECOTURISMO E TURISMO} DE AVENTURA. As práticas socioambientais no ecoturismo e no turismo de aventura - questionário socioambiental ABETA/primeiras análises. São Paulo, setembro de 2008. Disponível em: www.abeta.com.br. Acesso em: 25 de novembro de 2008. Não publicado.

ABETA. Diagnóstico do turismo de aventura no Brasil / ABETA e Ministério do Turismo. Belo Horizonte: Ed. dos autores, 2009. 156p. (Série Aventura Segura)

BARON, Robert A.; SHANE, Scott A. Empreendedorismo: Uma visão de processo. Cengage Learning, SP, 2011

BRASIL. Constituição (1988). Constituição da República Federativa do Brasil. Brasília, DF, Senado, 1998. 
BRASIL. Ministério do Turismo. Ecoturismo: orientações básicas. Secretaria Nacional de Políticas de Turismo, Departamento de Estruturação, Articulação e Ordenamento Turístico, Coordenação Geral de Segmentação. Brasília: Ministério do Turismo, 2008.

BRASIL. Ministério do Turismo. Ecoturismo: orientações básicas. / Ministério do Turismo, Secretaria Nacional de Políticas de Turismo, Departamento de Estruturação, Articulação e Ordenamento Turístico, Coordenação Geral de Segmentação. 2. ed. - Brasília: Ministério do Turismo, 2010.

BRASIL. Ministério do Turismo. Segmentação do Turismo: Marcos Conceituais. Brasília: Ministério do Turismo, 2006.

BRASIL. Ministério do Planejamento, Orçamento e Gestão. Economia Informal Urbana 2003. Instituto Brasileiro de Geografia e Estatística, 2005.

Dolabela, Fernando. O segredo de Luísa, 30a ed. São Paulo: Editora de Cultura, 2006.

CHIANCA, Érica. Falta de informação e medo de impostos contribuem para a informalidade. In: Agência Sebrae de Notícias PB, de 10/02/2011. Disponível em: http://www.pb.agenciasebrae. com.br/noticia.kmf?canal=819\&cod=11480413 Acesso em: 10/04/2011.

DOLABELA, Fernando. O Segredo de Luísa. São Paulo: Cultura Editores Associados, 1999.

DORNELAS, José Carlos Assis -Empreendedorismo - Transformando idéias em negócios Rio de Janeiro: Elsevier ,2008

GONÇALVES, Alexandre. Da Garagem para o Sucesso. In Revista Empreendedor; Editora Empreendedor, Ano 9, N 107, setembro 2003.

GURGEL, H.; Hargrave, J; França, F.; Holmes, R. M.; Ricarte, F. M.; Dias, B. F. S.; Rodrigues, C. G. O.; Brito, M. C. W. 2009. Unidades de conservação e o falso dilema entre conservação e desenvolvimento. Boletim Regional, Urbano e Ambiental, n3, dez. 2009, pp109-120.

KISHINAME, Roberto et al. Responsabilidade socioambiental das empresas. IN: CAMARGO, Aspésia; CAPOBIANCO, João Paulo R. \& OLIVEIRA, José Antonio Puppim. Meio ambiente Brasil: avanços e obstáculos pós-Rio 92. São Paulo: Estação Liberdade/Instituto Socioambiental. Rio de Janeiro: Fundação Getúlio Vargas, 2002. p. 377- 411. 
KRAMER, Randall et al. O papel do setor privado no estabelecimento e manejo de áreas protegidas. In: TERBORGH, J.; SCHAIK, C.; DAVENPORT, E. \& RAO, M. (orgs.) Tornando os parques eficientes: Estratégias para a conservação da natureza nos Trópicos. Curitiba: Editora UFPR / Fundação O Boticário de Proteção à Natureza, 2002. p. 363 - 380.

JULIÃO, Danielle et al. A influência das leis trabalhistas brasileiras na relação capital/ trabalho dos guias de turismo. Revista Acadêmica Observatório de Inovação do Turismo, Vol. 4, No 3 (2009)

LAYRARGUES,Philippe Pomier. A função social do ecoturismo. In: Boletim Técnico do Senac. Volume 30, no1. jan./abr. p. 39-45. 2004.

MCKERCHER, Bob. Turismo de Natureza: planejando sustentabilidade. São Paulo: contexto, 2002.

PIRES, Paulo S. Dimensões do ecoturismo. São Paulo: Editora SENAC, 2002.

RODRIGUES, C. G. O. 2009. O uso do público em parques nacionais: a relação entre as esferas pública e privada na apropriação da biodiversidade. Tese de Doutorado. Centro de Desenvolvimento Sustentável da Universidade de Brasília. Brasília (DF). 


\section{Sites consultados:}

http://lagoaaventuras.com.br/ Consultado em 17 de março de 2011.

http://material.nerea-investiga.org/publicacoes/user_35/FICH_PT_35.pdf A FUNÇÃO SOCIAL DO ECOTURISMO1

Layrargues. Philippe Pomier Consultado em 02 de fevereiro de 2011.

www.parquedacatacumba.com.br Consultado em 10 de novembro de 2010.

http://revistapegn.globo.com/Revista/Common/0,EMI167892-17180,00-PALESTRA+ MOSTRA+VANTAGENS+DA+FORMALIZACAO+PARA+SETOR+TURISTICO+NA+BAHIA.html Consultado em 5 de dezembro de 2010.

http://agoraparana.uol.com.br/index.php/cidade/sao-jose-dos-pinhais/1009-camara-setorial-de-turismo-incentiva-formalizacao-do-turismo-rural.html Consultado em 5 de dezembro de 2010.

\section{Mini currículo dos autores}

\section{Ana Pimentel}

Mestre em Psicossociologia de Comunidades e Ecologia Social na UFRJ e pós-graduada em Administração Hoteleira pela Scuola Internazionale di Scienze Turistiche (Roma). Sócia da Abaré Consultoria e atuante nas áreas de turismo sustentável, certificação, ecoturismo e turismo cultural. É consultora e auditora da norma NBR 15.401 (Sistema de Gestão da Sustentabilidade) e consultora cadastrada no Sebrae, Senac e Ministério do Turismo. Docente no MBA da Universidade Candido Mendes.anapimentelbr@yahoo.com.br

\section{Ayrton Violento}

Especialista em Turismo, Hotelaria e Entretenimento pela Universidade Candido Mendes. Engenheiro elétrico, especializado em Sistemas, formado pela Universidade Estadual do Rio de Janeiro (UERJ). Presidente da Confederação Brasileira de Esportes Populares, Caminhadas e Inclusão Social-ANDA BRASIL. Coordenador do setorial de Turismo da UNISOL Brasil. Presidente de honra e fundador da Associação Brasileira de Turismo Rural no Rio de Janeiro-ABRATURR.RJ. violento@andabrasil.com.br

\section{Camila Rodrigues}

Doutora em Políticas e Gestão Ambiental pelo Centro de Desenvolvimento Sustentável da Universidade de Brasília. Professora adjunta do Curso de Turismo e do Programa de Pós-graduação em Práticas em Desenvolvimento Sustentável, da Universidade Federal Rural do Rio de Janeiro. Sua trajetória profissional e acadêmica possui ênfase nas seguintes áreas: análise dos aspectos socioeoconômicos e ambientais do turismo; planejamento e gestão do turismo em áreas protegidas; políticas públicas na área ambiental; desenvolvimento e sustentabilidade.camirural@gmail.com

\section{Danielle Julião}

Mestre em Ciência Ambiental pela Universidade Federal Fluminense, Bacharel em Turismo pela Universidade Federal de Juiz de Fora ,com Especialização em Turismo pelo Observatório de Inovação do Turismo da FGV. Diretora de Turismo da Acolher Consultoria e Serviços; responsável pelo Departamento de Projetos Especiais da ETEAB/FAETEC; Especialista da Secretaria de Meio Ambiente do Estado de São Paulo e Consultora/Instrutora do Sebrae Nacional. Atua em projetos relacionados a área de políticas públicas, turismo, meio ambiente, empreendedorismo e educação.danicarj@gmail.com 


\section{Ester Juer}

Graduada (UFRJ), mestre (UERJ) e doutora (UERJ) em Ciências Sociais, pós-graduada em Gestão de Turismo (FGV/ EBAPE), Professora da Universidade Estácio de Sá nos cursos de Turismo, Hotelaria, Gastronomia. esterjuer@yahoo. com.br. Rua Marechal Mascarenhas de Moraes 190/103-Copacabana-Rio de Janeiro-RJ.

\section{Juliana Bastos Lohmann}

Mestre em Relações Internacionais pela UFF, pós graduada em Políticas Públicas para as Micro e Pequenas Empresas na Universidade Estadual de Campinas e em Turismo pelo Observatório de Inovação do Turismo no NT/EBAPE-FGV-RJ. Graduada em Ciências Sociais pela Universidade do Estado do Rio de Janeiro e atua como analista de políticas públicas pelo Sebrae/RJ.julilohmann@gmail.com 